\title{
A Systematic Method for the Design of Earthing System for Low-voltage Installations
}

\author{
Siow Chun Lim, Yousef Al-Shawesh
}

\begin{abstract}
Earthing system plays an essential role in electrical systems in terms of safety for people in the vicinity against the hazard of electric shocks as well as protection and proper operation of equipment during the incidence of electric faults by providing a low-impedance path that can dissipate fault currents to the conductive mass of earth. Engineers are faced with the design of adequate earthing systems that comply with national standards and regulations which apparently incorporate a variety of earthing methods and various formulae to obtain the design parameters such as the earthing resistance and conductor size. Manual calculation of such parameter makes the design quite laborious, tedious, and time-consuming but could conceivably be performed much quicker by a computer software. This paper presents a proposed step-by-step approach for the design of a reliable and effective earthing system for low-voltage installations. The main objective of this work is to develop a computer-aided and easy-to-use template which could be useful for industry practitioners in Malaysia who are responsible with earthing system design. A simple auto calculation software template was developed using Microsoft Excel spreadsheet. The template was tested by a consulting company in order to meet their industry needs. The developed template provides a technically acceptable computer simulation and yet a low-cost solution to the complex issue of effective design of earthing systems for low-voltage installations.
\end{abstract}

Index Terms: Earthing system, step voltage, standards, electrical safety, soil resistivity

\section{INTRODUCTION}

The design consideration of an earthing system in electrical installations is of paramount importance for providing sufficient safety of human life against electric shocks due to indirect contact with metallic parts and ensuring the protection and proper operation of equipment during normal and abnormal conditions as well as protection of structure buildings and equipment from lightning strokes and earth fault conditions due to unintentional contact with energised electrical lines. To avoid such instances, the electrical installation and conductive parts of the appliances must be earthed to ground so as to transfer the charge directly to earth. This can be achieved by establishing the lowest possible resistance path which allows the discharge and flow

Revised Manuscript Received on August 18, 2019.

Siow Chun Lim, Faculty of Engineering, Multimedia University, Cyberjaya, Malaysia

Yousef Al-Shawesh, Faculty of Engineering, Multimedia University, Cyberjaya, Malaysia. of lightning strikes and fault currents to ground earth with tolerable limits of touch and step voltages due to the rise in earth potential caused by the release of fault currents [1-2]. The earthing system should be designed and installed in a manner that limits the adverse consequences of earth potential gradients to such low levels of voltage and current that will not endanger the safety of people or equipment under both normal and fault conditions while ensuring the continuity of service.

One of the key essential requirements for designing an adequate earthing system is to have as low value as possible of resistance to remote earth in order to minimise the voltage between the earthing system and reference earth, known as earth potential rise (EPR) which is proportional to the magnitude of the fault current, and the earth resistance. A few key factors that determine the effectiveness of any earthing system are highly emphasised especially the soil resistivity depending on the surrounding environment as well as the size and configuration of the electrode. Most electrical engineering companies are encountered with the design of earthing systems. Installation of a well-designed earthing system is a fundamental requirement for all structures and electrical systems at all voltage levels which must strictly conform to national and international standards in certain respects. For low-voltage electrical installations safety and protection, a number of international standards have been published which define earthing techniques and earthing system design parameters.

Regulations pertaining to earthing systems differ to a notably large extent amongst countries, though many follow international standards proposed by some international organisations particularly for low-voltage installations. Low-voltage systems employ voltages in the range 50-1000 $\mathrm{V}$ AC or 120-1500 V DC as defined by IEC [3]. These voltages are most commonly known as the mains voltages as utilised by domestic, commercial, and light industrial premises [3]. Most of the available earthing standards propose a set of formulae and equations for calculating important parameters that aids in the design of a proper earthing system. Such earthing parameters include the earthing resistance and minimum size of the earthing conductor which can be calculated using various methods as part of the design methodology 


\section{A Systematic Method for the Design of Earthing System for Low-voltage Installations}

\section{METHOD}

The adoption of risk-based electrical earthing in most national and international standards can make the design of a safe earthing system more complicated than ever with its limited ranges of various design parameters that must be determined to ensure a low resistance path to ground earth. Earthing resistance is the most essential element of the design and thus it is prioritised. Soil resistivity is one of the fundamental parameters that determines the resistance and impedance of earthing as it essentially restrains the earthing electrode resistance. Therefore, the resistivity of soil where an earth electrode is buried shall be measured before the design of the earthing system. Besides, there is a number of components that determine the overall effectiveness of any earthing system comprising the earthing conductors and earthing electrodes that are used to construct the system. Selection of material, sizing, shape, configuration, and methods by which these individual elements are interconnected exerts influence on the performance, condition, and risk of such system. The level of fault current shall be determined, and the selection of earthing conductors size and material shall be decided. Earthing system must be meticulously designed so that the overall earthing resistance and the calculated mesh and step voltages fall below the tolerable limits as specified in the standards. This research work presents a proposed methodical step-by-step approach for the design of earthing systems for low-voltage installations based on BS-7430, IEEE-120 Green Book, and IEC-60364 [4, 5, 6] which are applied in practice in Malaysia. A simple software tool with auto-mathematical functions was developed using Microsoft Excel. This template is to provide a technically acceptable computer simulation and yet a low-cost solution to the complex issue of effective design of earthing systems according to the standards mentioned. Preliminary layout design is to be conducted after deciding the type of earthing electrode. The resistance of earthing must confirm to the minimum requirement. Further investigation of step and touch voltages is to be made to guarantee that they do not exceed the allowable limits. Nevertheless, if any of the three parameters still do not comply with standard regulations depending on the site soil conditions, alternative means of effective earthing methods must be considered in reducing the total earthing resistance and also the ground surface potential whenever design modification is necessary. For earthing resistance requirements, the following steps are proposed to be followed:

1) Obtain necessary information such as field soil resistivity, applicable area for electrode installation, and maximum fault current in the low-voltage installation.

2) Indicate in the design the standard requirements and customer design specifications if available.

3) Select the type, configuration, length, and diameter of earthing electrode according to type of soil and applicable area.

4) Calculate the earthing resistance for the electrode type and configuration.
5) Check if the calculated resistance meets the target value.

6) If resistance is still higher than minimum, then select alternative methods of earthing such as parallel connection of rods and concrete-encased electrode whenever possible while considering the cost and availability of electrodes.

7) Check if the new calculated resistance meets the design requirements.

8) Complete the design by including other necessary parameters for final design.

The entire procedure for designing an effective earthing system for low-voltage installations is illustrated in Fig. 1 which was modified from the chart proposed by IEEE-80 [7].

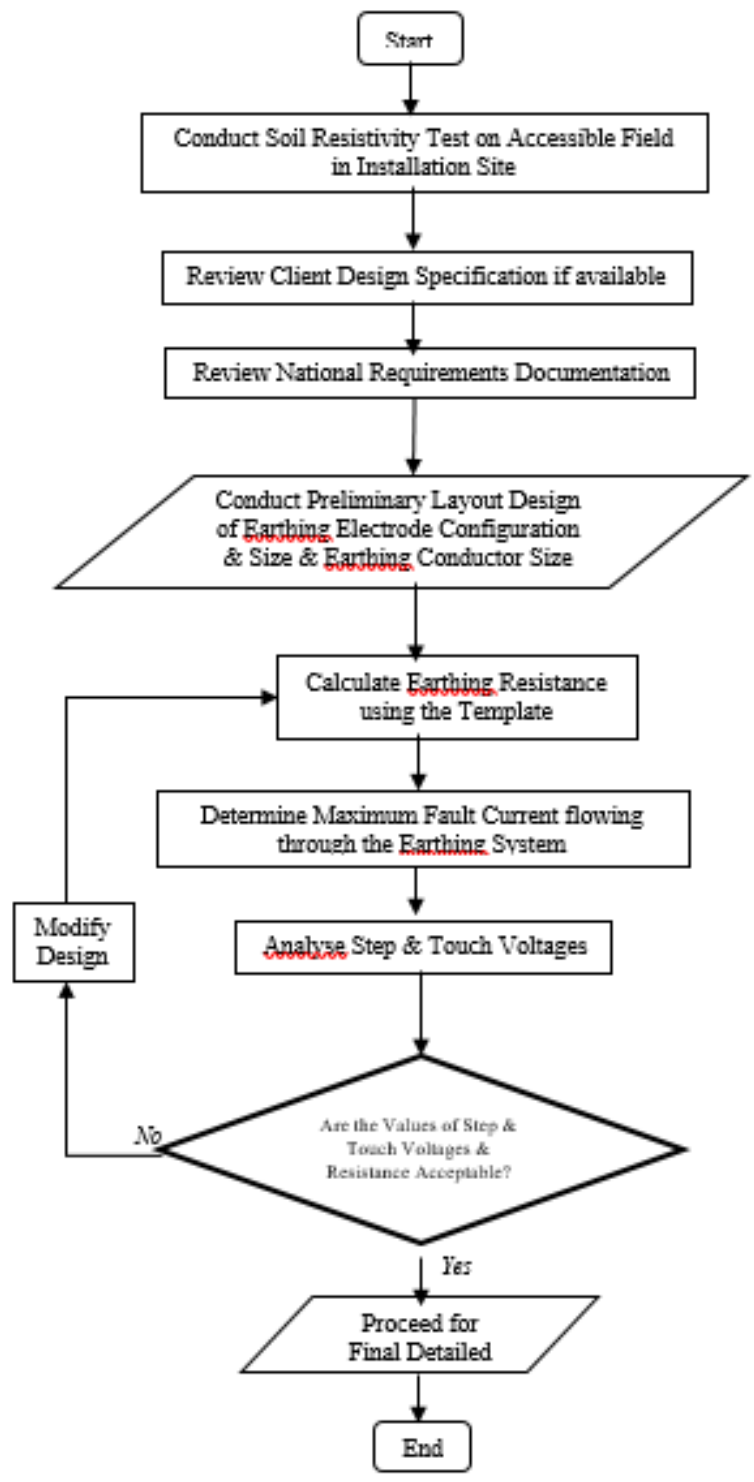

Fig 1: Flow chart of design procedure of earthing systems

\section{RESULTS AND DISCUSSIONS}

After identifying the parameters of earthing design specified in BS-7430, IEEE-120 Green Book, and IEC-60364 [4, 5, 6], data was entered into seven Microsoft Excel worksheets. The first worksheet incorporated mainly the formulae recommended by BS-7430 for calculating the earthing resistance for the various types of electrode 
configurations. Each electrode configuration data was categorised into three types; text, input constants, and Excel formula which computes the mathematical functions and then yields output results instantly. To enable the user to select the type of earthing, the dropdown list function was used. This allows the user to pick a text value from the dropdown list created with multiple options. The data of corresponding parameters to each earthing type was entered in cells below the cell containing the drop-down list. This data show only when a selection from the drop-down list was made. Comments were added to Excel cells where they can be read by the user while navigating by the computer mouse on the selected cells. These comments inform the user to either to pick a value from a drop-down list or to enter a constant number for the input parameters required to compute the output data correspondingly. The adjacent cells to the right of each parameter was highlighted with orange colour in the background where the user is to enter a valid constant number as a value for the corresponding adjacent parameter. Excel formula which always starts with an equal sign (=) contains numbers, functions such as $\mathrm{PI}()$ which returns the value pi: 3.142, references such as A1 which returns the value inside the cell $\mathrm{A} 1$, and mathematical operators for addition (+), subtraction (-),multiplication (*), division $(/)$, and $(\wedge)$ operator raises a number to a power. References in Excel are used to obtain the input values from the user as entered in the input highlighted cells. The function IF-nested was used extensively in our Microsoft Excel worksheets to make the template simple, neat and more effective for the user. This function makes a logical comparison between two values by testing for a condition and returning a result if True or False.

The template was designed so that user can select one of the 7 worksheets by clicking on its tab:

1) Procedure Flow Chart: this worksheet includes a proposed step-by-step approach for the design of earthing systems as described in Fig.1.

2) BS-7430 Resistance: this worksheet incorporates the calculation of earthing resistance for different types of earthing based on BS-7430.

3) BS-7430 Conductor Selection: this worksheet consists of various parameters selection procedure of materials and sizing of earthing electrodes based on BS-7430.

4) IEEE Green Book: this worksheet includes all formulae used for computing the earthing resistance as proposed by IEEE Green Book.

5) IEC 60364: this worksheet consists of sizing and selection of material of earthing conductors as recommended by IEC 60364 .

6) Common Methods: this worksheet incorporates the most common earthing methods applicable in Malaysia for electrode sizing and configuration based on selected target resistance and various values of soil resistivity as recommended by the consulting company.

7) Illustrations: this worksheet includes different figures and diagrams for the various configuration and earthing types.

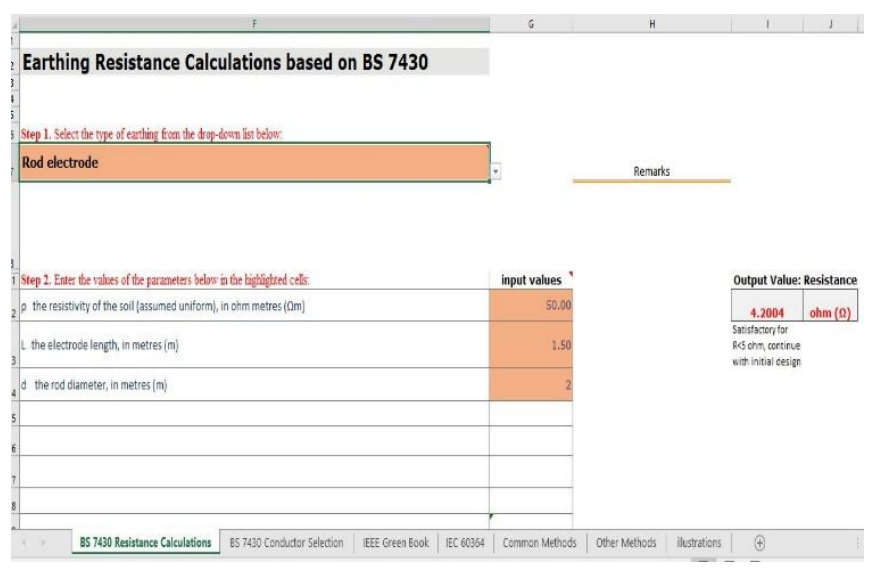

Fig 2: Screenshot of Template, BS-7430 Calculation of Earthing Resistance

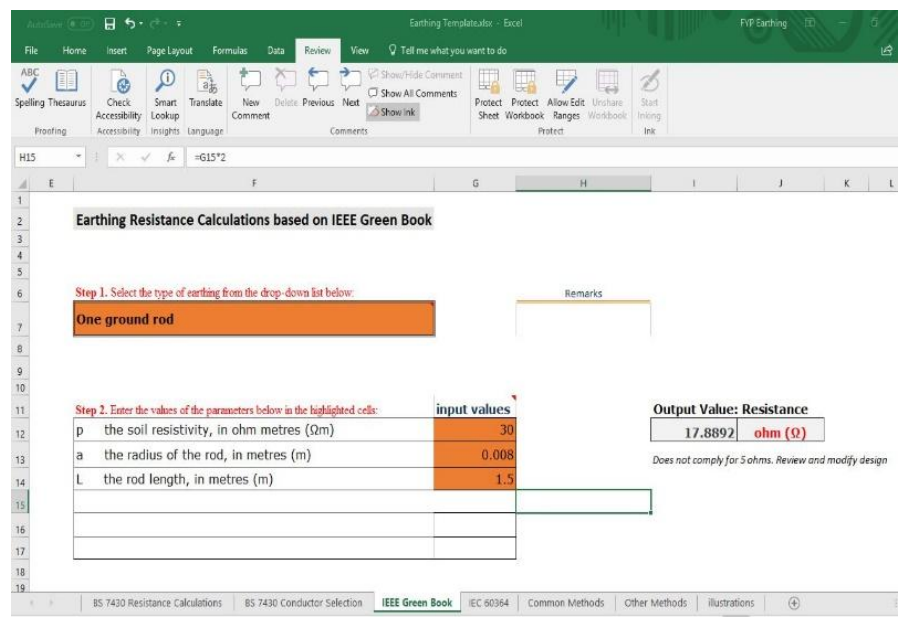

Fig 3: Screenshot of Template, IEEE Green Book, Calculation of Earthing Resistance

As can be seen from Fig. 2 and Fig. 3 above, the user needs to click on the downward arrow of the drop-down to select one type of earthing by clicking on the text as highlighted. The user then needs to enter valid values in the highlighted orange cells for the corresponding parameters described on the left for each parameter. These cells can be manipulated or modified by the user. The user can obtain the result from the grey cell for the earthing resistance for the earthing system chosen previously. The simulated values were verified by comparing them with the manually calculated values from the equations and tables given in the documentations of standards which produced the same results.

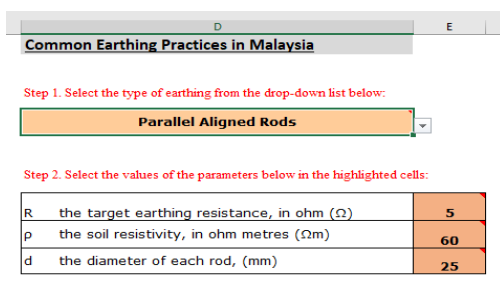

Output Data:

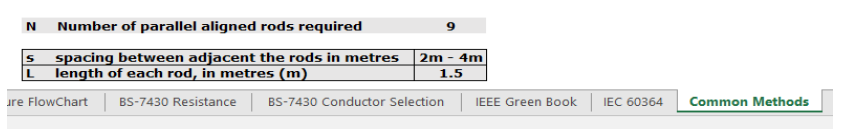

Fig 4: Screenshot of Template, Common Methods, Earthing Electrode Selection 


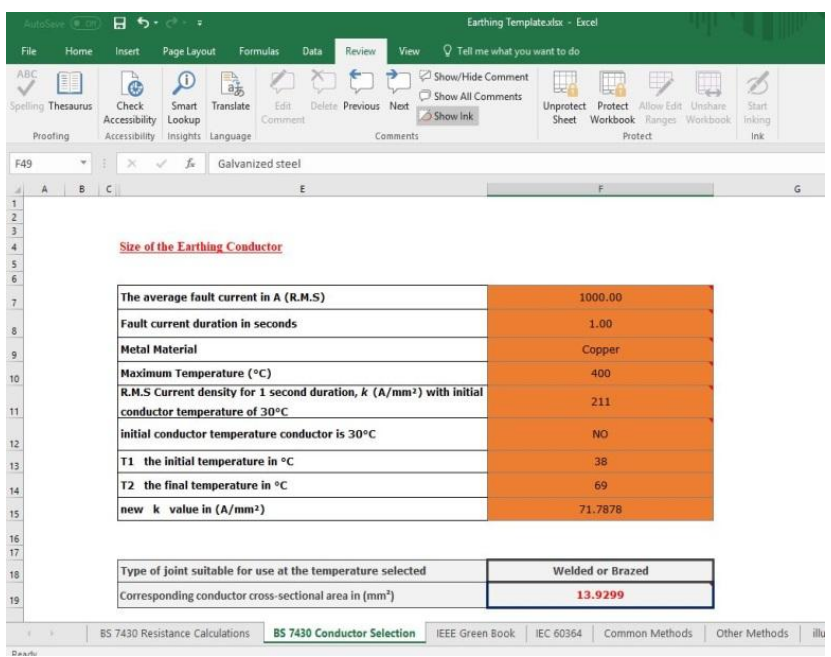

Fig 5: Screenshot of Template, BS-7430 Conductor Selection

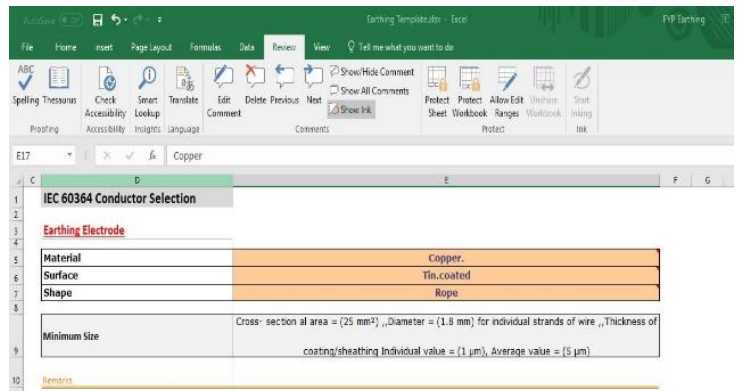

Earthins conductor buried in the soill

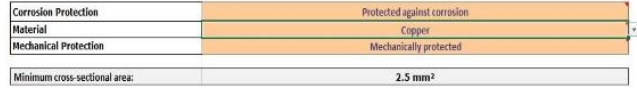

Supplementar Equipotentita Bonding Conductor

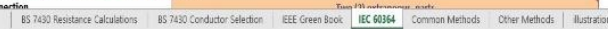

Fig 6: Screenshot of Template, IEC-60364 Conductor Selection

Further enhancement on the existing template can be made by including estimation of earth resistance using backfill material or ground improvement material as well as taking into account the effect of environmental factors such as proximity of earthing system to slopes and trees as reported in $[8-10]$.

\section{CONCLUSIONS}

A systematic and easy-to-follow approach for the design activities of earthing systems for low-voltage installations was proposed. A comprehensive, economically viable, and technically acceptable template was developed using Microsoft Excel which can be useful for industry engineers when designing earthing systems that comply with national and international standards applied in Malaysia. The use of this template was constantly verified throughout the development to execute accurate and precise results of design parameters in a time-saving manner.

\section{REFERENCES}

1. M. Nayel, Z. Jie, H. J. Liang, Cia , 'Study of step and touch voltages in Resistive/capacitive ground due to lightning stroke.', CEEE 2006, Dalian, 2PI-07, pp 56-60.

2. R. J. Heppe."Step Potentials and Body Currents near Grounds in Two Layer Earth," IEEE Transaction on Power Apparatus and System Voltages, vol. PAS-98, No.1, pp 45-59, Jan./Feb., 1979.
3. MS IEC Electrical installations of buildings - Guide to IEC 60364 (First Revision), Draft Malaysian Standard 14E006R1, Standards Malaysia, 2014.

4. British Standards Institution. BS 7430: 2011. Code of practice for protective earthing of electrical installations. Milton Keynes: BSI, 2011.

5. IEEE Standard-142 (Green Book), IEEE Recommended Practice for Grounding of Industrial and Commercial Power Systems; 2007.

6. MS IEC 60364, Electrical Installations of Buildings, Part 5-54: Selection and Erection of Electrical Equipment: Earthing Arrangements, Protective Conductors and Protective Bonding Conductors, IEC 60364-5-54: 2004

7. Institute of Electrical and Electronics Engineers. IEEE 80: 2000. Guide for Safety in AC Substation Grounding. New York: IEEE, 2000.

8. C. Gomes, M.Z.A.Ab.Kadir, C. L. Kottachchi, and S.C. Lim, "Industrial Waste and Natural Substances for Improving Electrical Earthing System", International Journal of Electrical Engineering, April 2014.

9. S. C. Lim, L. W. Choun, C. Gomes, and M. Z. A. A. Kadir, "Environmental effects on the performance of electrical grounding systems," in Power Engineering and Optimization Conference (PEOCO), 2013 IEEE 7th International, 2013, no. June, pp. 330-333.

10. S. C. Lim, G. Nourirad, C. Gomes, and M. Z. A. A. Kadir, "Significance of localized soil resistivity in designing a grounding system," in Power Engineering and Optimization Conference (PEOCO), 2014 IEEE 8th International, 2014, March

\section{AUTHORS PROFILE}

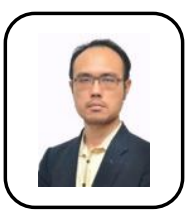

Siow Chun Lim obtained his bachelor's degree in electrical and electronic engineering from Universiti Putra Malaysia in 2011. He then completed his $\mathrm{Ph} \mathrm{D}$ in electrical power engineering specializing in electrical grounding systems in 2014. In 2017, he was the International Electrotechnical Commission (IEC) Young Professional candidate representing Malaysia. He is also the Honorary Secretary cum Treasurer of the National Working Group of ASEAN Engineering Inspectorate (Electrical Installation) which focusses on harmonization of electrical engineering standards. His main research interests include electrical earthing system, lightning protection and engineering education.

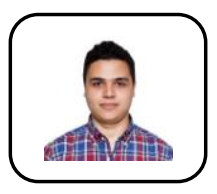

Yousef Al-Shawesh obtained his bachelor's degree in electrical engineering from Multimedia University in 2018. During his undergraduate studies, he volunteered as a teaching assistant at the Faculty of Engineering for three trimesters, conducting extra tutorial sessions for Digital Logic Design, Circuits \& Signals, and Power Transmission \& Distribution. His bachelor's thesis focused on the development of an auto-calculation software tool, for the design of a safe earthing system for industry practitioners in Malaysia. 